RESEARCH

SERIES

NUMBER 86

March 2019

\section{THE IMPACT OF A CHANGE IN THE NATIONAL MINIMUM WAGE ON THE DISTRIBUTION OF HOURLY WAGES AND HOUSEHOLD INCOME IN IRELAND}

PAUL REDMOND, KARINA DOORLEY AND SEAMUS MCGUINNESS

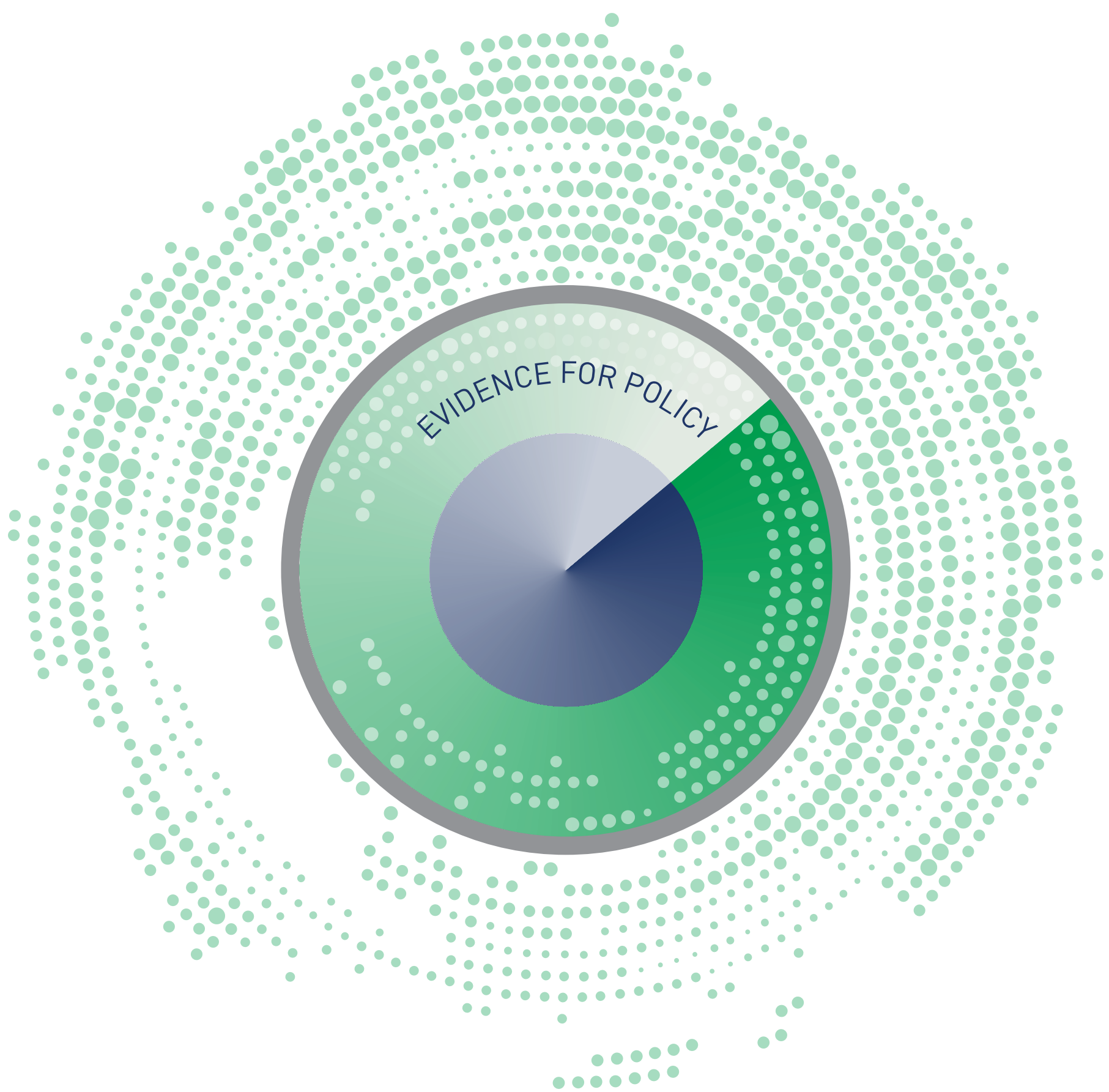




\title{
THE IMPACT OF A CHANGE IN THE NATIONAL MINIMUM WAGE ON THE DISTRIBUTION OF HOURLY WAGES AND HOUSEHOLD INCOME IN IRELAND
}

\author{
Paul Redmond \\ Karina Doorley \\ Seamus McGuinness
}

March 2019

Available to download from www.esri.ie

(C) The Economic and Social Research Institute

Whitaker Square, Sir John Rogerson's Quay, Dublin 2

ISBN 978-0-7070-0482-2

DOI https://doi.org/10.26504/rs86.pdf

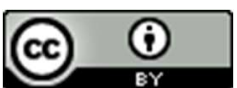

This Open Access work is licensed under a Creative Commons Attribution 4.0 International License (https://creativecommons.org/licenses/by/4.0/), which permits unrestricted use, distribution, and reproduction in any medium, provided the original work is properly credited. 


\section{ABOUT THE ESRI}

The mission of the Economic and Social Research Institute is to advance evidencebased policymaking that supports economic sustainability and social progress in Ireland. ESRI researchers apply the highest standards of academic excellence to challenges facing policymakers, focusing on 12 areas of critical importance to 21 stcentury Ireland.

The Institute was founded in 1960 by a group of senior civil servants led by $\mathrm{Dr}$ T.K. Whitaker, who identified the need for independent and in-depth research analysis to provide a robust evidence base for policymaking in Ireland.

Since then, the Institute has remained committed to independent research and its work is free of any expressed ideology or political position. The Institute publishes all research reaching the appropriate academic standard, irrespective of its findings or who funds the research.

The quality of its research output is guaranteed by a rigorous peer review process. ESRI researchers are experts in their fields and are committed to producing work that meets the highest academic standards and practices.

The work of the Institute is disseminated widely in books, journal articles and reports. ESRI publications are available to download, free of charge, from its website. Additionally, ESRI staff communicate research findings at regular conferences and seminars.

The ESRI is a company limited by guarantee, answerable to its members and governed by a Council, comprising 14 members who represent a cross-section of ESRI members from academia, civil services, state agencies, businesses and civil society. The Institute receives an annual grant-in-aid from the Department of Public Expenditure and Reform to support the scientific and public interest elements of the Institute's activities; the grant accounted for an average of 30 per cent of the Institute's income over the lifetime of the last Research Strategy. The remaining funding comes from research programmes supported by government departments and agencies, public bodies and competitive research programmes.

Further information is available at www.esri.ie 


\section{THE AUTHORS}

Paul Redmond is a Research Officer at the ESRI and Adjunct Assistant Professor at Trinity College Dublin. Karina Doorley is a Senior Research Officer at the ESRI, an Adjunct Lecturer at Trinity College Dublin and a Research Fellow at the Institute for Labor Studies (IZA). Seamus McGuinness is a Research Professor at the ESRI and Adjunct Professor at Trinity College Dublin.

\section{ACKNOWLEDGEMENTS}

The work carried out in this report was funded by the Low Pay Commission. We would like to thank all individuals within the Commission who provided assistance during the project and provided us with valuable comments on earlier drafts of the report. We would also like to thank the Central Statistics Office for access to the data used in the study. 


\section{CONTENTS}

Executive Summary

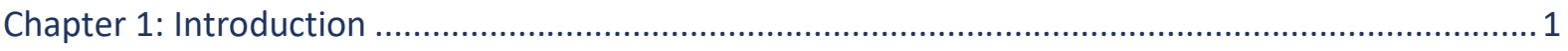

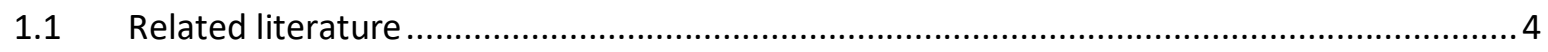

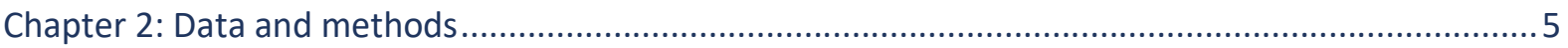

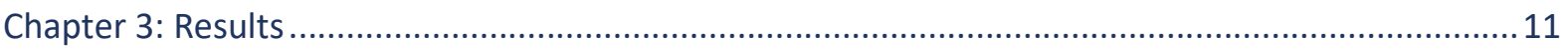

3.1 The effect of the minimum wage change on male wages ................................................15

3.2 The effect of the minimum wage change on female wages ................................................ 16

3.3 The effect of the minimum wage change on young employees.........................................18

3.3 The effect of the minimum wage change on household income .......................................19

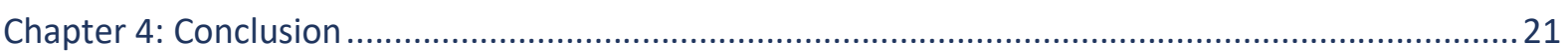

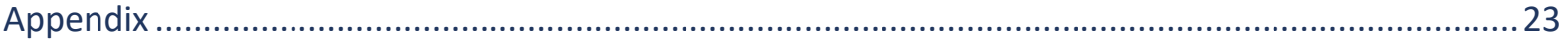

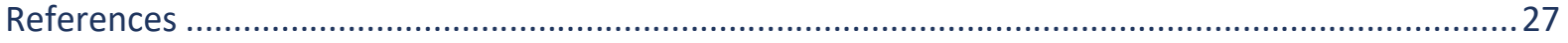




\section{LIST OF TABLES}

Table 2.1 Percentage of workers earning €9.15 per hour or below............................................... 6

Table 3.1 Impacts of 2016 NMW change on average wages and inequality (all employees) ..........14

Table 3.2 Impacts of 2016 NMW change on average wages and inequality (males only) ...............16

Table 3.3 Impacts of $2016 \mathrm{NMW}$ change on average wages and inequality (females only)............17

Table 3.4 Measures of inequality and average wages of low-paid workers (young workers only) 19

\section{LIST OF FIGURES}

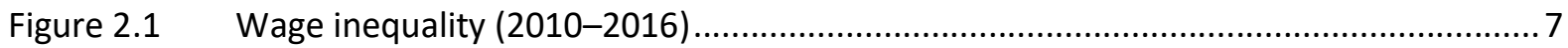

Figure 3.1 Actual and counterfactual 2016 hourly wage distributions.......................................11

Figure 3.2 Price and composition effects of the minimum wage change....................................12

Figure $3.3 \quad$ Minimum wage effect and confidence intervals ......................................................13

Figure $3.4 \quad$ Minimum wage effect (males only) ........................................................................ 16

Figure $3.5 \quad$ Minimum wage effect (females only) .................................................................. 17

Figure $3.6 \quad$ Minimum wage effect (young employees only) ...................................................... 18

Figure 3.7 Effect of minimum wage increase on household incomes .........................................20

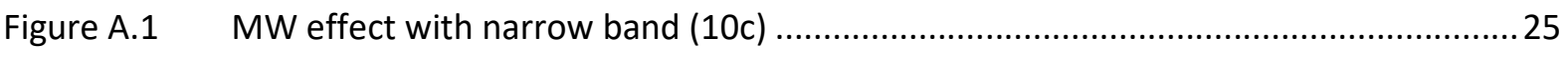

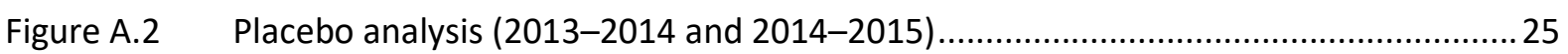




\section{ABBREVIATIONS}

CDF

cumulative distribution function

DR

distributional regression

LFS

Labour Force Survey

SILC

Survey of Income and Living Conditions 


\section{EXECUTIVE SUMMARY}

- In January 2016, the national minimum wage in Ireland increased from €8.65 to €9.15 per hour, an increase of approximately $6 \%$. In this study, we investigate the effect of this minimum wage increase on the distribution of hourly wages and gross household income.

- This study uses novel techniques to estimate the impact of the 2016 minimum wage increase on the distribution of earnings in Ireland. Our results show clear impacts on the hourly wage distribution that are centred around the new minimum wage level. These effects are observed for all workers and separately for males, females and young people.

- Our evidence suggests that without the minimum wage change, approximately $10 \%$ of workers in 2016 would have earned €9.15 per hour or below. However, following the increase in the minimum wage, just over $6 \%$ of workers had an hourly wage in this range. Therefore, the evidence suggests that the minimum wage change was associated with a 4 percentage point (or $40 \%$ ) reduction in the number of workers earning $€ 9.15$ per hour or below.

- The results point towards potential wage spillover effects to workers earning above the minimum wage, with statistically significant wage effects detected up as far as $€ 11.50$ per hour.

- We estimate that the increase in the minimum wage resulted in a $2 \%$ increase in the average hourly wage of workers earning between $€ 6.50$ and $€ 11.50$ per hour. The impacted wage range, i.e. those earning between $€ 6.50$ and $€ 11.50$, accounts for approximately the bottom $25 \%$ of the wage distribution.

- With respect to wage inequality, our analysis indicates that the increased minimum wage led to a reduction of $8 \%$ in the P90/P10 ratio and $4 \%$ in the P75/P25 ratio. This supports the view that increases in the minimum wage decrease levels of wage inequality in the labour market.

- There is no strong evidence to indicate that the increase in the minimum wage impacted the distribution of gross household incomes. This is consistent with other literature which shows that the minimum wage may be a blunt tool for reducing poverty, as minimum wage workers are often located in households at the higher end of the income distribution. 



\section{CHAPTER 1}

\section{Introduction}

A national minimum wage (NMW) was first introduced in Ireland in April 2000 at a rate of $€ 5.58$ per hour. ${ }^{1}$ Several increases occurred in subsequent years, so that by July 2007 the minimum wage stood at $€ 8.65$ per hour. From 2008 onwards Ireland experienced a prolonged economic downturn, which coincided with a period of nine years during which the minimum wage did not increase. In 2015, against the backdrop of an economic recovery, the Irish Low Pay Commission was established and tasked with providing yearly recommendations to the Irish government concerning the appropriate rate for the Irish minimum wage. To date, all of the Low Pay Commission recommendations have been implemented by government.

On 1 January 2016 the minimum wage increased from $€ 8.65$ per hour to $€ 9.15$ per hour. There were further increases on 1 January 2017, to €9.25 per hour, on 1 January 2018, to $€ 9.55$ per hour and on 1 January 2019, to $€ 9.80$ per hour. It should be noted that sub-minimum rates, expressed as a percentage of the full rate, exist for employees under 18 years of age (70\%), employees in their first year of employment (80\%), employees in their second year of employment $(90 \%)$ and employees in structured training during working hours $\left(75 \%, 80 \%\right.$ or $90 \%$, depending on level of progression). ${ }^{2}$ However, the incidence of this type of employment is very low. Of all individuals on or below minimum wage, approximately $90 \%$ earn the minimum wage, with just $10 \%$ on sub-minimum rates (McGuinness and Redmond, 2018).

Minimum wages can be seen as a policy tool to ensure fair pay for low-paid workers with low bargaining power. In this regard, the Low Pay Commission makes recommendations which are based on achieving a fair and sustainable minimum wage to assist as many low-paid workers as possible without creating significant adverse consequences for employment or competitiveness. However, the degree to which an NMW can alleviate poverty or impact income inequality is not entirely clear. While there is evidence to indicate that the minimum wage in Ireland is an effective tool in protecting the income of low-skilled workers, especially during recessions (Holton and O'Neill, 2017), the Low Pay Commission (2016) acknowledges that it may be a blunt tool in tackling poverty. Logue and Callan (2016) suggest that it is an inefficient way to boost the income of poor families, as

Or $£ 4.40$ in Irish pounds.

See www.lowpaycommission.ie for further details on the sub-minimum rates, including what qualifies as 'structured training'. 
a substantial portion of the increased earnings go to those in the higher end of the income distribution. $^{3}$

Factors such as compliance, spillover effects and employment effects will also influence the impact of increases in the NMW on inequality. If there is a lack of compliance with minimum wage legislation, this will lessen the impact of minimum wage increases on inequality. Compliance, by its very nature, is difficult to quantify. However, the Workplace Relations Commission, a state agency with responsibility for promoting employment law, found that $13 \%$ of employment law breaches in Ireland in 2017 related to the minimum wage. ${ }^{4}$ Wage spillover effects to individuals earning in excess of the minimum wage will likely reduce inequality, as low-wage workers who earn slightly above the minimum wage will also see a pay rise.

In terms of employment effects, McGuinness and Redmond (2018) find no increase in the likelihood of job losses among minimum wage workers after the 2016 rate rise. However, there is some evidence of a reduction in hours worked, in the order of 0.5 hours per week, which could limit the effect of the minimum wage increase on inequality. ${ }^{5}$ Even with this type of hours reduction, though, the average minimum wage worker would still see a net increase in their pay. In our dataset, minimum wage employees work, on average, 30 hours per week. The increase in the minimum wage from $€ 8.65$ to $€ 9.15$ would result in a $€ 15$ weekly increase for such workers. If hours were reduced by 0.5 hours per week, the net weekly increase would be $€ 10.43$. ${ }^{6}$

In this report, we analyse the effect of the 2016 minimum wage increase on the distribution of hourly wages in Ireland. To do so, we employ a technique similar to that of Bargain et al. (2018). This involves constructing a counterfactual wage distribution, which is an estimate of what the wage distribution would have looked like in 2016 absent a minimum wage increase. By comparing this counterfactual distribution to the actual 2016 distribution, we can precisely isolate what part of the wage distribution, if any, was most affected by the minimum wage change. As such, our distributional analysis allows us to analyse how wage inequality in the population of workers changed due to the change in the NMW, as well as to

3 According to Eurostat, income inequality in Ireland in 2016, measured as the ratio of income in the top $20 \%$ to the bottom $20 \%$ of households, was below the European average. Income inequality in Ireland was the 16th highest out of 28 countries. See https://ec.europa.eu/eurostat/web/products-eurostat-news/-/EDN-20180426-1

4 See Redmond and McGuinness (2018) for a further discussion of minimum wage enforcement and compliance in Ireland.

5 McGuinness and Redmond (2018) note that some of the reduction in hours may have been due to an income effect, whereby more part-time minimum wage workers entered the labour market at the higher wage. This is supported by the finding that involuntary part-time employment fell among minimum wage workers after the 2016 increase.

$6 \quad$ With sufficient sample sizes, our distributional regression could potentially be extended to analyse the effect of the minimum wage change on the hours distribution of minimum wage workers, by looking at changes in the hours distributions of minimum wage workers before and after the rate increase. However, we do not have a sufficiently large sample size for this. 
measure the impact on the average hourly earnings of the most affected groups. Therefore, an advantage of this methodology is that it allows us to detect narrow impacts on the wage distribution that may be missed using standard linear regression techniques, which focus only on average wages, or even quantile regression techniques which analyse discrete intervals of the wage distribution.

The results of our distributional analysis indicate that the 2016 increase in the NMW had a statistically significant impact on the wages of low-paid workers. Our results suggest that, in the absence of a minimum wage change, approximately $10 \%$ of workers in 2016 would have earned $€ 9.15$ per hour or below. However, following the minimum wage change, just $6 \%$ of workers had an hourly wage in this range. Therefore, the evidence indicates that the minimum wage change was associated with a 4 percentage point (or $40 \%$ ) reduction in the number of workers earning €9.15 per hour or below. For young workers (aged 25 years or less), we observe a potential 10 percentage point reduction in the probability of earning $€ 9.15$ per hour or below. There is also evidence of statistically significant wage spillover effects as far up as $€ 11.50$ per hour in the wage distribution. While we cannot discount the possibility that some of these spillovers may be attributable to measurement error in calculating hourly wages, the strength of the evidence is consistent with genuine spillover effects. With respect to wage inequality, the evidence suggests that the increased minimum wage was associated with a reduction of approximately $8 \%$ in the P90/P10 ratio and approximately $4 \%$ in the P75/P25 ratio. ${ }^{7}$

We also study the effect of the minimum wage change on income inequality, using two definitions of income. The first is monthly household employment income, equivalised using the modified OECD scale. This takes account of the wage income of all household members. Given that we are evaluating the impact of a wage policy, it is useful to restrict the analysis to employment income, as one would expect the income effects to manifest themselves through changes in household wages.

The second measure is annual household gross income, equivalised using the modified OECD scale. This encompasses all forms of household income. However, a drawback of this measure is that annual income contains a mix of 2015 and 2016 incomes, depending on the date of interview, whereas the first measure, of employment income, relates only to 2016. There is no strong evidence that the minimum wage change affected either measure. This is consistent with previous findings that the minimum wage may be a blunt tool for reducing poverty. This is 
because minimum wage workers are often located in households at the higher end of the income distribution and are typically not primary earners within households.

\subsection{RELATED LITERATURE}

While most minimum wage studies tend to focus on the effect of minimum wage changes on employment outcomes (see e.g. McGuinness and Redmond (2018) for Ireland), a strand of the minimum wage literature focuses specifically on the distributional effects of minimum wage policies. The closest work to ours is that of Dickens and Manning (2004a, 2004b), who investigate the effect of the UK minimum wage on wage inequality. They detect modest effects, but find no strong evidence of wage spillovers. In contrast, Autor et al. (2016) find a strong association between wage inequality and the minimum wage in the US, and attribute much of this to spillover effects, whereby workers earning above the minimum wage saw their wages increase. Evidence of this type of wage spillover is also found by Neumark et al. (2004).

Garnero et al. (2015) investigate how different minimum wage policies across 18 European countries affect earnings inequality, and find that countries with statutory minimum wages typically have lower levels of wage inequality. Similarly, Maurizio and Vazquez (2016), focusing on Latin America, find that increases in minimum wages in Argentina, Brazil and Uruguay led to a substantial decline in wage inequality due to compression at the lower end of the distribution. Belman et al. (2015) carry out a meta-analysis using minimum wage studies across multiple developed countries over the period 2000 to 2015, and find that higher minimum wages are often associated with higher earnings and lower inequality.

However, other studies suggest that minimum wage policies are inefficient tools in tackling poverty and inequality. MaCurdy (2015) simulates the distributional impacts of the 1996 minimum wage increase in the US and finds that approximately one quarter of the after-tax earnings increase goes to families in the top $40 \%$ of the wage distribution. Logue and Callan (2016) find a similar result for Ireland. Using microsimulation analysis, they find that few low-paid individuals are in households with incomes below $60 \%$ of the median. Consequently, increases in the minimum wage primarily lead to increases in disposable income in the upper half of the income distribution. Therefore, both MaCurdy (2015) and Logue and Callan (2016) suggest that minimum wage policies are limited tools for boosting the incomes of poor families. 


\section{CHAPTER 2}

\section{Data and methods}

The data used in our analysis come from the Survey of Income and Living Conditions (SILC) microdata, provided by the Central Statistics Office (CSO) in Ireland. SILC collects information on income and living conditions by means of household interviews, which take place on a continuous weekly basis throughout the year. We calculate hourly wages by dividing gross monthly income by the usual number of hours worked by the employee, which we use to investigate the impact of the minimum wage increase on the hourly wage distribution. In addition, we examine household wages by adding together the monthly wage income of all employees within the household. ${ }^{8}$

The SILC data also contain information on annual gross household income. While our measure of household wages includes only employment income, gross household income includes all forms of income. However, the income reference period is the 12 months immediately prior to the date of the interview. As such, the income reference period for 2016 spans from January 2015 to December 2016. Therefore, a drawback of the household income measure is that annual income may contain a mix of 2015 and 2016 incomes, depending on the date of interview.

Participation in the SILC survey is voluntary for the selected survey respondents. The overall response rate in 2015 was $60 \%$ and the sample size was 13,793 individuals. The overall response rate in 2016 was $58 \%$ and the sample size was 13,186 individuals. As the focus of our study is on the impact of the increase in the minimum wage on hourly wages and wage inequality, our sample consists of employees only, of whom there were 3,899 in 2015 and 3,641 in 2016.

The minimum wage increased from $€ 8.65$ to $€ 9.15$ per hour in January 2016 . In 2016, the SILC data indicate that $6.5 \%$ of all employees were earning $€ 9.15$ per hour or below. Note that in quarter 2 of 2016, a question was added to the Irish Labour Force Survey (LFS) which directly asks employees whether they earn above, on, or below the minimum wage. The incidence of minimum wage employment in 2016, using this new LFS question, is $10 \%$, which is higher than the $6.5 \%$ using SILC data. ${ }^{9}$ When calculating hourly wages using SILC, we are dividing monthly earnings by the employee's self-reported usual hours of work. Therefore, some degree of measurement error is unavoidable. If measurement error is leading to a greater degree of overestimation of hourly wages in SILC, then our SILC incidence of minimum wage employment will be understated compared to LFS. In this scenario,

We use equivalised wage income and the OECD modified scale.

While the LFS contains an indicator of minimum wage status which is useful for calculating the incidence of minimum wage employment, it does not contain wage or earnings data and therefore cannot be used in our analysis. 
some SILC workers earning slightly above €9.15 per hour should actually be classified as minimum wage workers. However, measurement error does not appear to be causing any significant distortion to the distribution of hourly wages in SILC. While the LFS data indicate that $10 \%$ of workers in 2016 earned $€ 9.15$ per hour or below, the SILC data show that $10 \%$ of workers earned $€ 9.50$ per hour or below.

Table 2.1 shows the percentage of employees earning $€ 9.15$ per hour or below in both 2015 and 2016, using SILC data. We show this for the overall population of workers, as well as separately for three groups: males, females and young people (age 25 or less). The increase in the minimum wage, from $€ 8.65$ to $€ 9.15$ in January 2016 , coincided with a sharp reduction in the incidence of workers earning $€ 9.15$ or below. This went from $11.13 \%$ in 2015 to $6.48 \%$ in 2016 . The results by gender show that the percentage of males and females in this wage range is roughly similar, with the incidence of low-wage employment being slightly higher for females. The two groups experienced similar reductions in the incidence of lowwaged employment over the two time periods. The incidence among young workers is much higher. In 2015, 35\% of young workers (aged 25 or under) earned $€ 9.15$ per hour or below, compared to $25 \%$ in 2016 . These descriptive statistics indicate that the 2016 increase in the minimum wage appears to have boosted the hourly wage of a substantial number of low-wage employees. ${ }^{10}$

\begin{tabular}{|l|c|c|}
\hline All employees & 2015 & 2016 \\
\hline Males & 11.13 & 6.48 \\
& $(n=3,899)$ & $(n=3,641)$ \\
\hline Females & 10.25 & 6.36 \\
& $(n=1853)$ & $(n=1761)$ \\
\hline Young workers (aged 25 or less) & 11.93 & 6.60 \\
& $(n=2046)$ & $(n=1880)$ \\
& 35.10 & 24.55 \\
& $(n=416)$ & $(n=387)$
\end{tabular}

Wage inequality in Ireland, which is one of our key outcomes in this study, has been relatively stable in recent years. We can examine wage inequality by comparing the ratio of hourly wages of workers in the 90th and 10th percentiles (the P90/P10 ratio) and also the 75th and 25th percentiles (the P75/P25 ratio). Figure 2.1 shows the P90/P10 and P75/P25 statistics for gross hourly wages in Ireland from 2010 to 2016. These ratios measure the earnings gap between workers at the bottom and top of the wage distribution and, as such, are indicators of the level of wage

10 Regarding the composition of minimum wage employees, $55 \%$ are female compared to $45 \%$ male, which matches almost exactly the figures using the LFS data. Approximately $35 \%$ of minimum wage workers are aged under 25. 
inequality present in the labour market. The P90/P10 ratio has changed little over the period. In 2010 it stood at 3.9, and was slightly lower in 2016 at 3.7. There was even less movement in the P75/P25 ratio, which stood at approximately 2.2 for the entire period.

FIGURE 2.1 WAGE INEQUALITY (2010-2016)

Source: Survey of Income and Living Conditions (2010-2016).

In our analysis, we use distributional regression (DR). This is a flexible way to model wage distributions. It fits a separate model, relating hourly wages to demographic information (age, education, marital status, contract type (permanent/temporary), worker type (full-time/part-time), gender and nationality (Irish/non-Irish)) at every point of the wage distribution in both 2015 and 2016. Using the 2015 model coefficients and the 2016 data, we simulate what the wage distribution in 2016 would have looked like if there was no increase in the minimum wage. ${ }^{11}$ Comparing the 2016 wage distribution to this 'counterfactual' 2016 distribution allows us to identify the effect of the minimum wage.

In practical terms, our analysis involves running a series of probit models at each point of the wage distribution in 2015 . The dependent variable is binary and takes the value of 1 if an individual has an hourly wage below $w$, and 0 otherwise, where $w$ takes the value of each point of the wage distribution sequentially. In our baseline analysis, $w$ was increased at 50c intervals for all hourly wages in the $€ 5$ to

11 This method assumes that there were no other major policy changes around the same time period that may have shifted the wage distribution. Given that our results show the price effect is concentrated exactly around the new minimum wage, we are confident that we are capturing the effect of the minimum wage change. 
$€ 40$ range. ${ }^{12}$ We choose a relatively wide range as the sample size can be limited in the tails of the distribution, especially when we look at subsamples of minimum wage workers, such as males, females and young people. However, we verify the robustness of our baseline estimates by increasing $w$ at 10c intervals for the full sample. We show that our results are robust to using both narrow and wide ranges. The models are used to predict the probability that an individual has a wage below $w$. The model coefficients for 2015 are then applied to individuals in the 2016 data to construct a counterfactual wage distribution, which is an estimate of what the wage distribution in $\mathbf{2 0 1 6}$ would have looked like in the absence of a minimum wage change. The observed difference between the actual 2016 wage distribution and the counterfactual 2016 distribution can therefore be attributed to any policy change that altered labour market conditions in the second period, which in our case relates to the minimum wage increase. A more formal explanation of the approach is given in the appendix.

This methodology allows us to measure the impact of the 2016 minimum wage change on levels of wage inequality in Ireland. A priori, we may expect any policy that improves the position of low-waged workers to reduce the gap between highand low-paid workers, thus reducing wage inequality. We assess the impact of the minimum wage change on wage dispersion by comparing the counterfactual P90/P10 and P75/P25 ratios to the actual 2016 statistics. A fall in these ratios, as a result of the minimum wage change, would be consistent with a fall in wage inequality. We also identify the precise wage range that was affected by the minimum wage change in a statistically significant way, thereby identifying the extent to which low-paid workers were affected. As well as capturing the effect on minimum wage workers, it highlights any wage spillovers that may have occurred for workers earning in excess of the minimum wage. The extent of spillover effects is captured by measuring the degree to which the average wages of workers have been affected in the areas of the wage distribution just above the new minimum wage level. In addition to applying this methodology to the full sample of employees, we restrict our analysis to three subsamples: males, females and young workers (aged 25 years and under). ${ }^{13}$

We also investigate the effect of the increase in the minimum wage on income inequality. To do this, we use the DR method, outlined above, to model gross household income before and after the increase in the minimum wage. Gross

12 We exclude hourly wages above $€ 40$ per hour, which amounts to approximately the top $5 \%$ of hourly wages. The support in the upper tail beyond this point is too low to carry out meaningful analysis with our distributional regression techniques.

13 Another subsample of interest is non-Irish nationals. However, implementing this methodology requires an adequate sample size across the wage distribution. There were too few observations for non-Irish nationals to apply the methodology. 
income is equivalised using the OECD modified equivalence scale. ${ }^{14}$ Explanatory variables in the model include characteristics of the household head (age, age squared, education, marital status, a dummy for Irish nationality, labour market status) as well as an indicator for the number of other earners in the household and the number of weekly labour hours provided by the household. ${ }^{15}$ Using the coefficients from the model of gross income before the minimum wage increase, we predict the distribution of gross income in the absence of a minimum wage increase. The difference between the predicted 2016 gross income distribution and the actual 2016 gross income distribution gives the effect of the minimum wage increase on the gross income distribution.

14 The first adult is assigned a weight of 1 , other adults are assigned a weight of 0.5 and children (under 14 years of age) are assigned a weight of 0.3 .

15 Coefficients from specific points of this model and graphs showing the fit of the predicted distributions are available on request. 



\section{CHAPTER 3}

\section{Results}

Figure 3.1 plots the actual and counterfactual 2016 hourly wage distributions. The difference between the distributions is greatest in the region of the 2016 minimum wage of $€ 9.15$ (represented by the red vertical line), which suggests that the increase in the minimum wage had a distributive impact, as it is unlikely that any other factor would have induced such a significant shift in this segment of the wage distribution. The fact that the actual wage distribution lies below the counterfactual distribution indicates that there were fewer low-paid workers in 2016 than would have been the case had there been no minimum wage change.

\section{FIGURE 3.1 ACTUAL AND COUNTERFACTUAL 2016 HOURLY WAGE DISTRIBUTIONS}

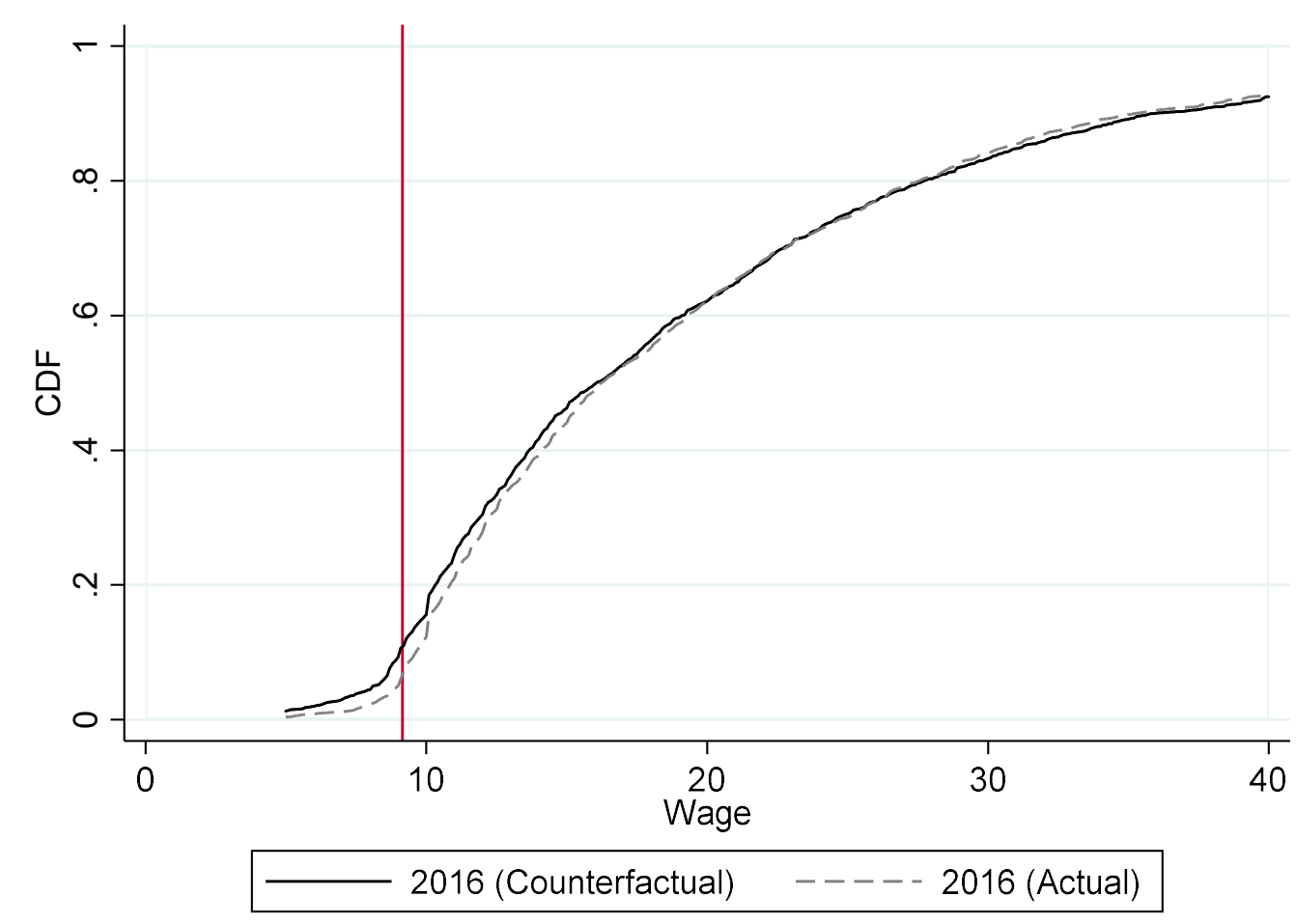

In order to get a clearer picture of this gap, Figure 3.2 plots the difference between the 2015 and 2016 cumulative distribution functions (CDFs) across the hourly wage range (the Total Difference line). This difference is then decomposed into the proportion of the gap that is attributable to the minimum wage change (the minimum wage (MW) effect) and the proportion that is attributable to a compositional change, i.e. changes to the education, age, gender, nationality or contract profiles of workers in 2016 compared to 2015 (the compositional effect 
line). We see that at the lower end of the wage distribution, virtually all of the gap between the actual and the counterfactual CDFs is attributable to the minimum wage change, i.e. the MW effect line is very similar to the total difference line.

\section{FIGURE 3.2 PRICE AND COMPOSITION EFFECTS OF THE MINIMUM WAGE CHANGE}

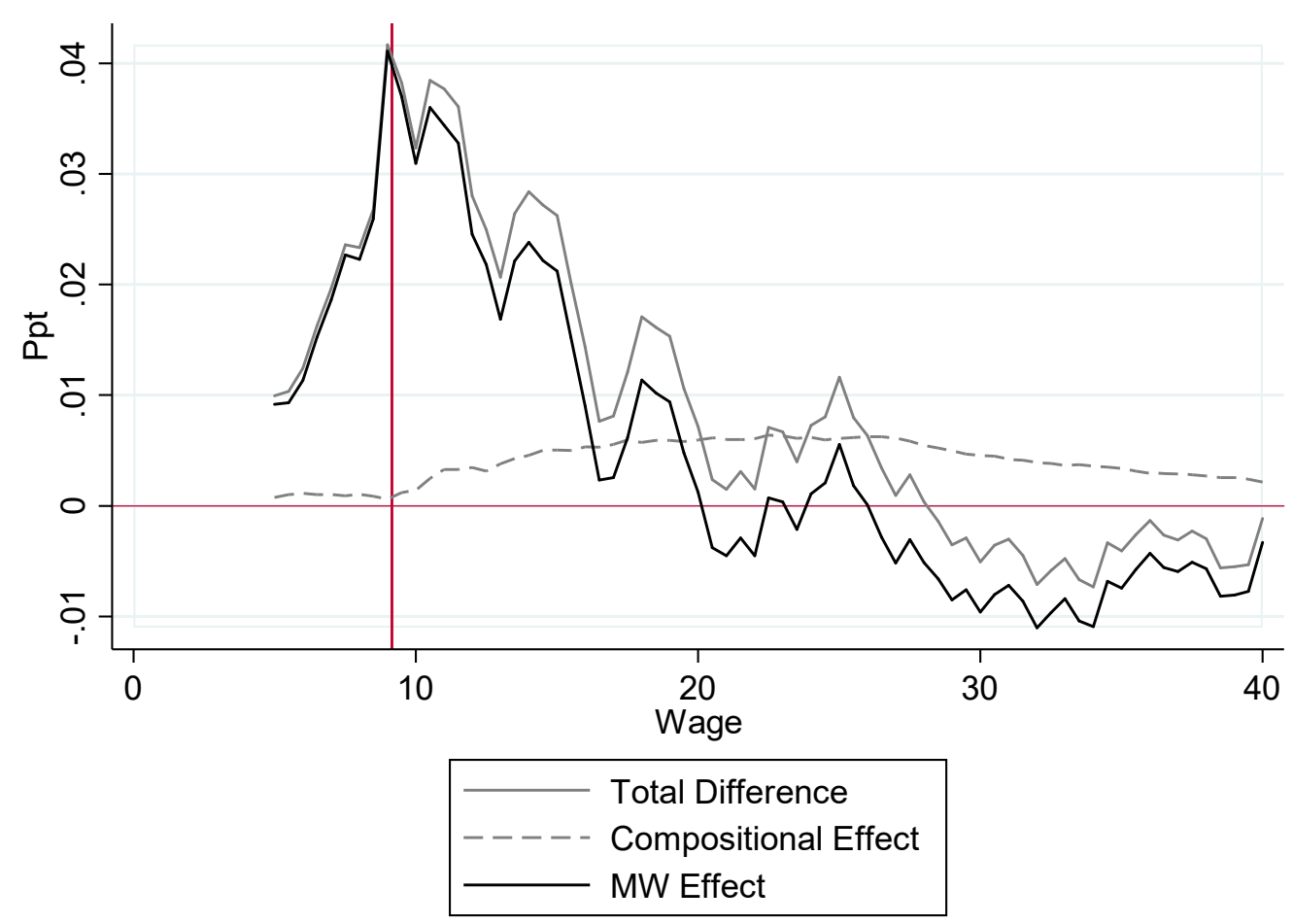

Note: $\quad$ Ppt $=$ percentage points

It is not clear that all of the observed price effects shown in Figure 3.2 are statistically significant. To more accurately pinpoint the affected wage range, we generate standard errors that allow us to identify the wage range where the price effect is statistically significant. ${ }^{16}$ Figure 3.3 plots the MW effect along with fitted 95\% confidence intervals. ${ }^{17}$ The area of the wage distribution with the greatest statistically significant MW effect corresponds to the new minimum wage rate of $€ 9.15$ (the vertical red line). Taken together, Figures 3.1-3.3 indicate that in the absence of a minimum wage change, approximately $10 \%$ of workers in 2016 would have earned $€ 9.15$ per hour or below. However, following the minimum wage change, just over $6 \%$ of workers had an hourly wage in this range. Therefore, the minimum wage change potentially resulted in a 4 percentage point reduction in the number of workers earning $€ 9.15$ per hour or below (which corresponds to the

16 The model is bootstrapped, with 250 replications.

17 As a robustness test, we estimate the model using $10 \mathrm{c}$ intervals instead of $50 \mathrm{c}$ intervals. The results are unchanged (see Figure A.1 in the appendix). 
peak of 0.04 in Figures 3.2 and 3.3).

Figure 3.3 also points towards wage spillover effects, as we observe a statistically significant price effect up to $€ 11.50$ per hour. This type of wage spillover effect is consistent with the findings of Autor et al. (2016) and Neumark et al. (2004) for the US. However, it stands in contrast to Dickens and Manning (2004a, 2004b) who find no wage spillover effects associated with the UK minimum wage. It is important to note that some of the apparent spillover effects that we detect in our analysis could relate to measurement error when it comes to calculating the hourly wage rate. This would be the case if some workers with estimated hourly wages slightly in excess of €9.15 per hour were actually minimum wage workers earning exactly €9.15 per hour. However, given that we observe a statistically significant impact as far up the wage distribution as $€ 11.50$ per hour, and given the apparent limited impact of measurement error on the wage distribution, which we discussed in detail in Chapter 2, it is likely that these impacts are genuine.

\section{FIGURE 3.3 MINIMUM WAGE EFFECT AND CONFIDENCE INTERVALS}

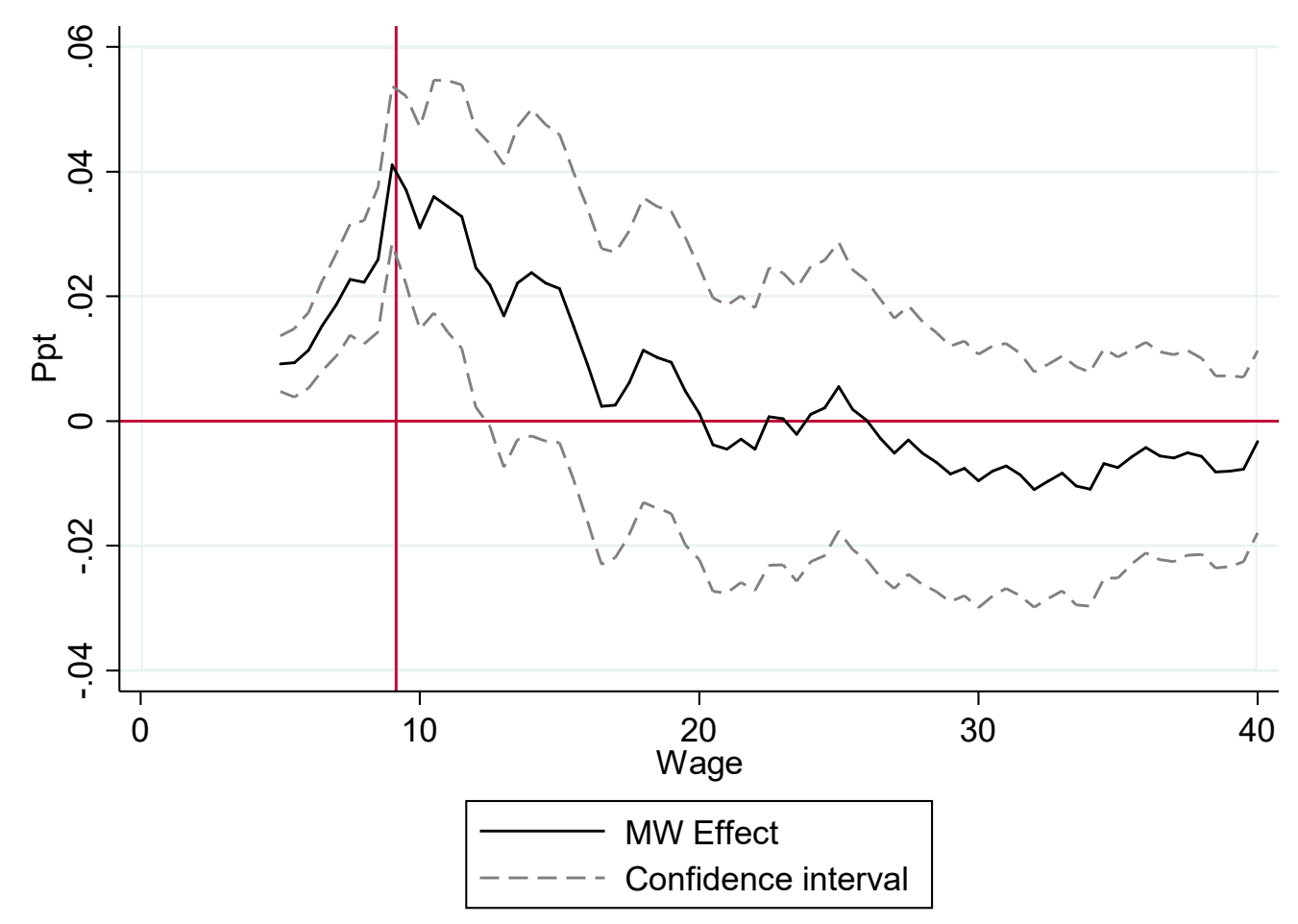

Note:

Ppt = percentage points

In order to get an estimate of the impact of the minimum wage change on the hourly wage rate of affected workers, we compare the 2016 counterfactual average hourly wage of workers in the range where a statistically significant minimum wage effect was detected, $€ 6.50$ to $€ 11.50$, with the actual hourly wages 
of workers in this range during 2016. This is shown in Table 3.1. The average hourly wage in 2016 of workers in this wage range was $€ 10.09$. In the absence of a minimum wage increase, our estimated counterfactual distribution reveals that the average hourly wage in this wage range would have been $€ 9.87$ per hour. ${ }^{18}$ Therefore, the increase in the minimum wage was associated with a $2 \%$ increase in the average hourly wage of workers earning between $€ 6.50$ and $€ 11.50$ per hour. The impacted wage range, i.e. those earning between $€ 6.50$ and $€ 11.50$, accounts for approximately the bottom $25 \%$ of the wage distribution. ${ }^{19}$

TABLE 3.1 IMPACTS OF 2016 NMW CHANGE ON AVERAGE WAGES AND INEQUALITY (ALL EMPLOYEES)

\begin{tabular}{l|l|c|c}
\hline & Full sample & $\mathbf{2 0 1 6}$ & Counterfactual \\
& P90/P10 & 3.68 & 3.98 \\
& P75/P25 & 2.17 & 2.25 \\
& Average wage in range $€ 6.50-€ 11.50$ & 9.87 & 10.09 \\
& Observations & 7,412 & 7,412 \\
\hline & & &
\end{tabular}

The minimum wage increase is likely to have benefited more females than males, given the higher representation of females (56\%) compared to males (44\%) among these low earners. A significant number of young workers, aged 25 or less, will also benefit from minimum wage increases, as $27 \%$ of all workers earning $€ 6.50$ to $€ 11.50$ per hour fall within this age category.

To measure the potential impact of the minimum wage change on wage inequality, we report the ratio of the 75th to 25th percentiles (P75/P25) of the wage distribution. An increase (decrease) in the P75/P25 ratio indicates that inequality will have risen (fallen) as a consequence of the 2016 rate change. In 2016, the P75/P25 was 2.17, indicating that the hourly wage of those in the 75th percentile was 2.17 times greater than that of those in the 25th percentile. The P75/P25 from our counterfactual distribution was higher at 2.25. This suggests that P75/P25 inequality would have been slightly higher without the increase in the minimum wage. Using this particular metric, inequality fell by approximately $4 \%$ following the 2016 NMW increase. Likewise, our P90/P10 estimate in 2016 was 3.68, versus 3.98 for the counterfactual distribution, again indicating that the minimum wage increase was associated with a reduction in hourly wage inequality, this time in the

18 When comparing the average wages from two distributions in a specific range, the slope of the CDFs as well as their relative position (which one lies above the other) can affect the averages. However, in our case, while the actual lies below the counterfactual in this range, the slopes of the two CDFs are similar. Therefore, comparing averages within this range allows us to get a useful estimate of the effect on wages.

19 There are very few workers earning less than $€ 6.50$ per hour either before or after the change in the NMW. 
order of $8 \%$ using this metric. Therefore, our results suggest that the 2016 minimum wage increase was associated with a decrease in wage inequality.

To verify the robustness of our results, we carry out a placebo test by implementing our DR technique on previous year pairings (2013-2014 and 2014-2015), where no minimum wage change occurred. Should we find similar results in the placebo years, indicating significant changes to the wage distribution centred at $€ 9.15$, this would call into question our ability to attribute our 2016 findings to the 2016 minimum wage change. However, as we see in Figure A.2 in the appendix, the placebo years show no such findings. For 2013 to 2014, the price effect is zero and is not statistically significant. For 2014-2015, the price effect is not statistically significant, apart from a negative effect, at approximately $€ 14$ in the wage distribution. Therefore, the placebo tests indicate that our observed wage distribution effects in $\mathbf{2 0 1 6}$ did not occur in previous years where there was no minimum wage change. Furthermore, if the negative effects observed in the placebo test in 2014-2015 were part of a general, continuing trend, then our 2016 estimates would actually understate the effect of the 2016 minimum wage increase.

\subsection{THE EFFECT OF THE MINIMUM WAGE CHANGE ON MALE WAGES}

We carry out the same analysis, this time restricting our focus to male employees. Figure 3.4 shows the effect of the minimum wage on the male wage distribution. As with the full sample of employees, the effect is greatest at the new minimum wage of $€ 9.15$ per hour, reaching a maximum of 0.04 . Therefore, the minimum wage change is associated with a 4 percentage point reduction in the number of workers earning €9.15 per hour or below.

We also observe wage spillovers for male employees as far up as $€ 11$ per hour. Table 3.2 shows the average hourly wage within this range for the actual 2016 distribution as well as the counterfactual distribution. In 2016, the average male wage in this range was $€ 9.92$ per hour, whereas in the absence of a minimum wage change, this would have been $€ 9.69$ per hour, thereby indicating that the minimum wage change increased the average male wage in this region by $2.3 \%$. The minimum wage change was also associated with a potential reduction of $11 \%$ in P90/P10 male wage inequality and a reduction of 5\% in P75/P25 inequality. 


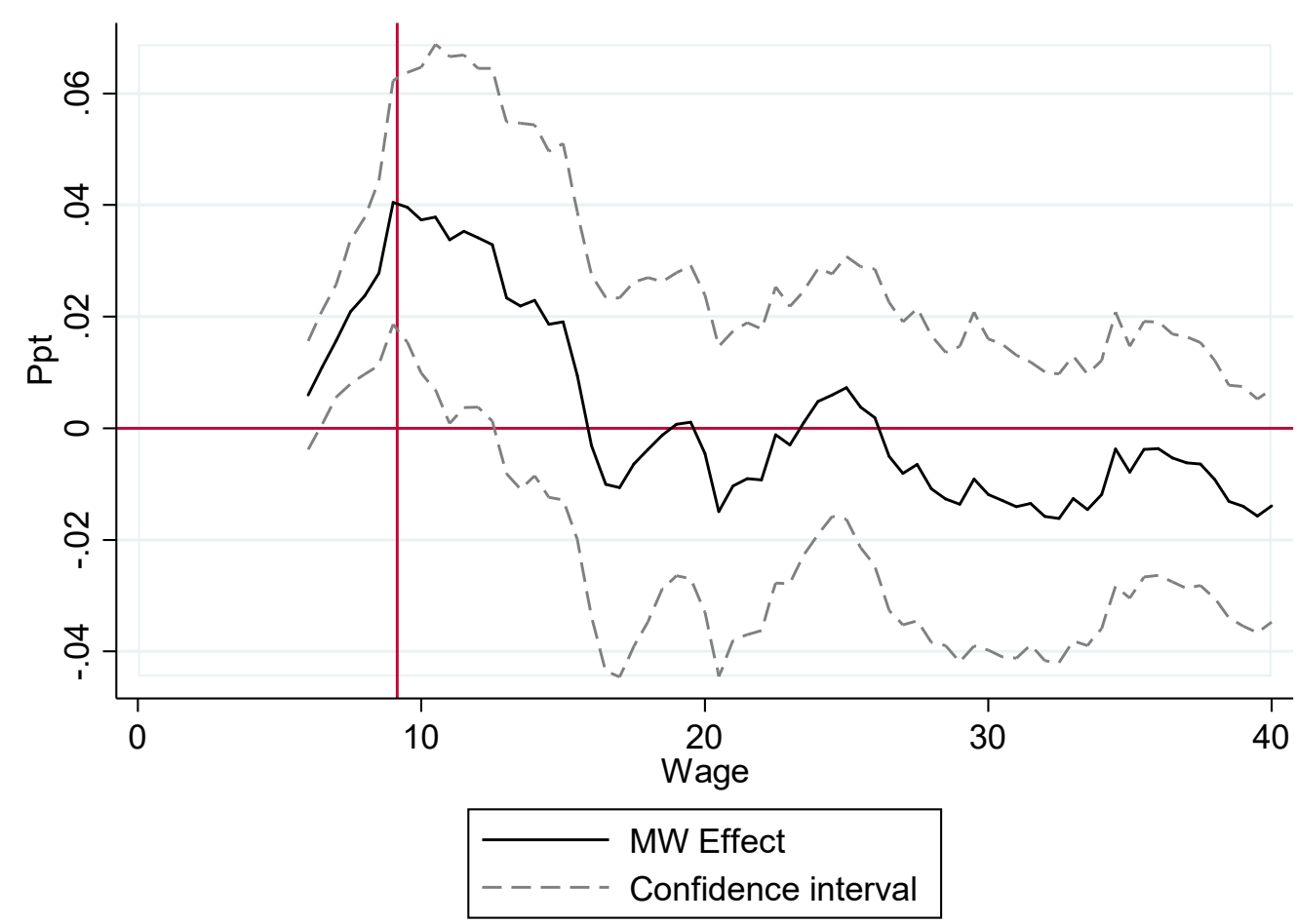

Notes: The vertical red line indicates the 2016 minimum wage (€9.15). The dashed grey lines indicate the region in the distribution where the minimum wage effect is statistically significant $(€ 7-€ 11)$. Ppt $=$ percentage points.

TABLE 3.2 IMPACTS OF 2016 NMW CHANGE ON AVERAGE WAGES AND INEQUALITY (MALES ONLY)

\begin{tabular}{|l|c|c|}
\hline Males only & $\mathbf{2 0 1 6}$ & Counterfactual \\
\hline P90/P10 & 3.74 & 4.17 \\
\hline P75/P25 & 2.18 & 2.30 \\
\hline Average wage in range $€ 7.50-€ 11$ & 9.92 & 9.69 \\
\hline Observations & 3,534 & 3,534 \\
\hline
\end{tabular}

Source: $\quad$ SILC (2010-2016).

\subsection{THE EFFECT OF THE MINIMUM WAGE CHANGE ON FEMALE WAGES}

The effect of the 2016 minimum wage change for females is very similar to that for males. Figure 3.5 shows the effect of the change in the minimum wage on the wage distribution. As before, the effect is greatest at the new minimum wage of $€ 9.15$ per hour. The potential effect is slightly larger than that for males, at approximately 4.5 percentage points.

The potential wage spillover effects are also similar to those for males. Table 3.3 shows the actual and counterfactual average female wage within the affected 
region. While the average wage in 2016 was $€ 9.82$ per hour, it would have been $€ 9.72$ (1.2\% lower) in the absence of a minimum wage change. Table 3.2 also shows a reduction in female P90/P10 and P75/P25 wage inequality of $8.6 \%$ and $4.6 \%$ respectively.

\section{FIGURE 3.5 MINIMUM WAGE EFFECT (FEMALES ONLY)}

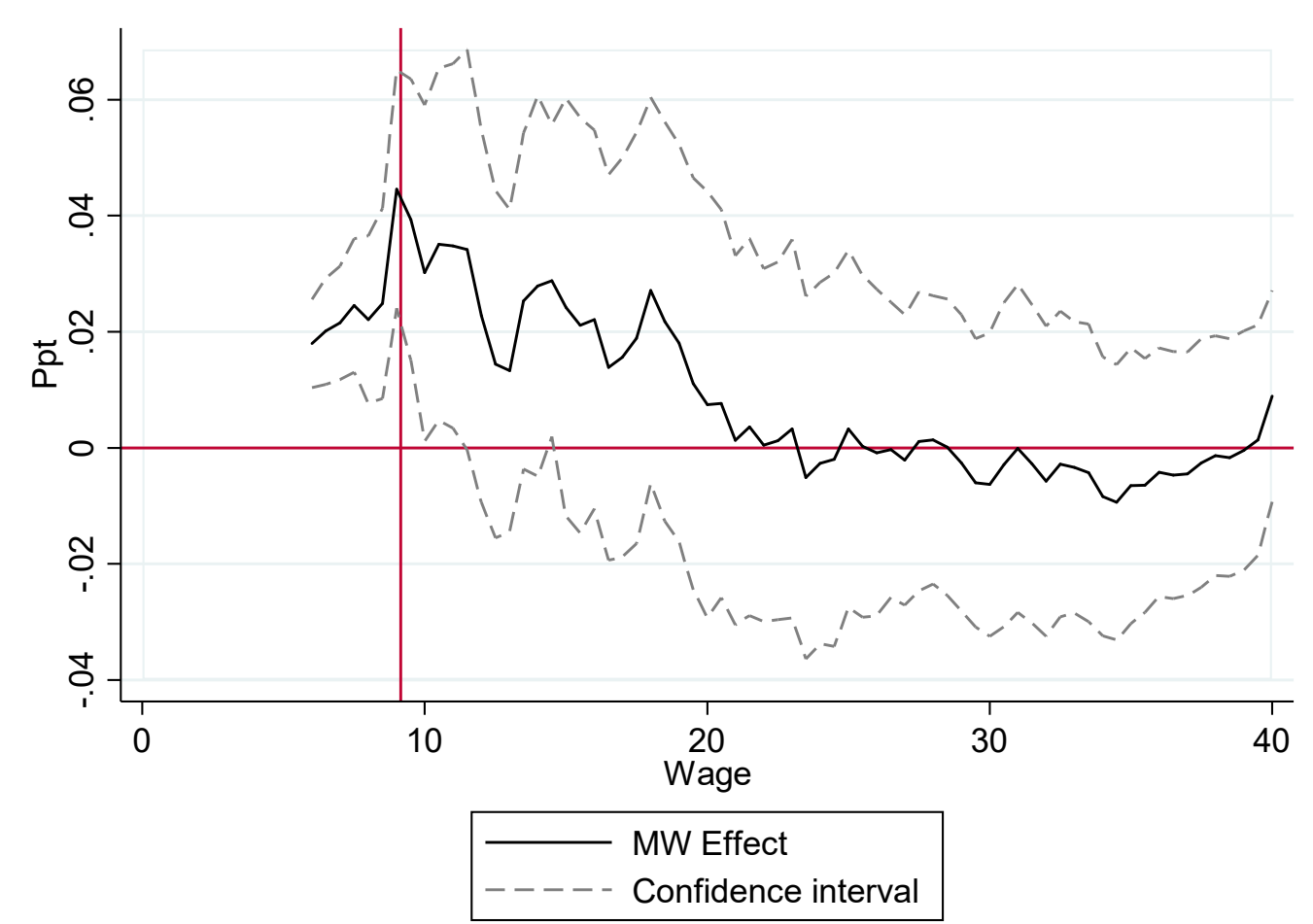

Note: $\quad$ The vertical red line indicates the 2016 minimum wage (€9.15). The dashed grey lines indicate the region in the distribution where the minimum wage effect is statistically significant $(€ 6.50-€ 11)$. Ppt $=$ percentage points.

TABLE 3.3 IMPACTS OF 2016 NMW CHANGE ON AVERAGE WAGES AND INEQUALITY (FEMALES ONLY)

\begin{tabular}{|l|c|c|}
\hline Females only & $\mathbf{2 0 1 6}$ & Counterfactual \\
\hline P90 / P10 & 3.57 & 3.89 \\
\hline P75 / P25 & 2.14 & 2.24 \\
\hline Average wage in range $€ 6.50-€ 11$ & 9.82 & 9.70 \\
\hline Observations & 3,878 & 3,878 \\
\hline
\end{tabular}

Source: $\quad$ SILC (2010-2016). 


\subsection{THE EFFECT OF THE MINIMUM WAGE CHANGE ON YOUNG EMPLOYEES}

We investigate the effect of the minimum wage change on young employees, defined as those aged 25 years or less. Figure 3.6 shows the estimated effect of the change in the minimum wage across the wage distribution for young workers. As before, the estimated effect is greatest around the 2016 minimum wage of €9.15. However, the magnitude of the effect, in percentage point terms, is higher, as the increase in the minimum wage in 2016 is associated with a 10 percentage point reduction in young employees earning on or below $€ 9.15$ per hour.

The estimated spillover effects for this group of young workers are not as large as for the general population of workers. The wage range where we observe a statistically significant effect is concentrated between $€ 6.50$ and $€ 9.50$. In Table 3.4, we show that the average wage in this range in 2016 was $€ 8.90$ per hour. In the absence of a minimum wage change this would have been $€ 8.59$ per hour, approximately $3.5 \%$ lower. The minimum wage increase was associated with an estimated reduction in the P90/P10 and P75/P25 measures of wage inequality for young workers of $27 \%$ and $4 \%$ respectively.

\section{FIGURE 3.6 MINIMUM WAGE EFFECT (YOUNG EMPLOYEES ONLY)}

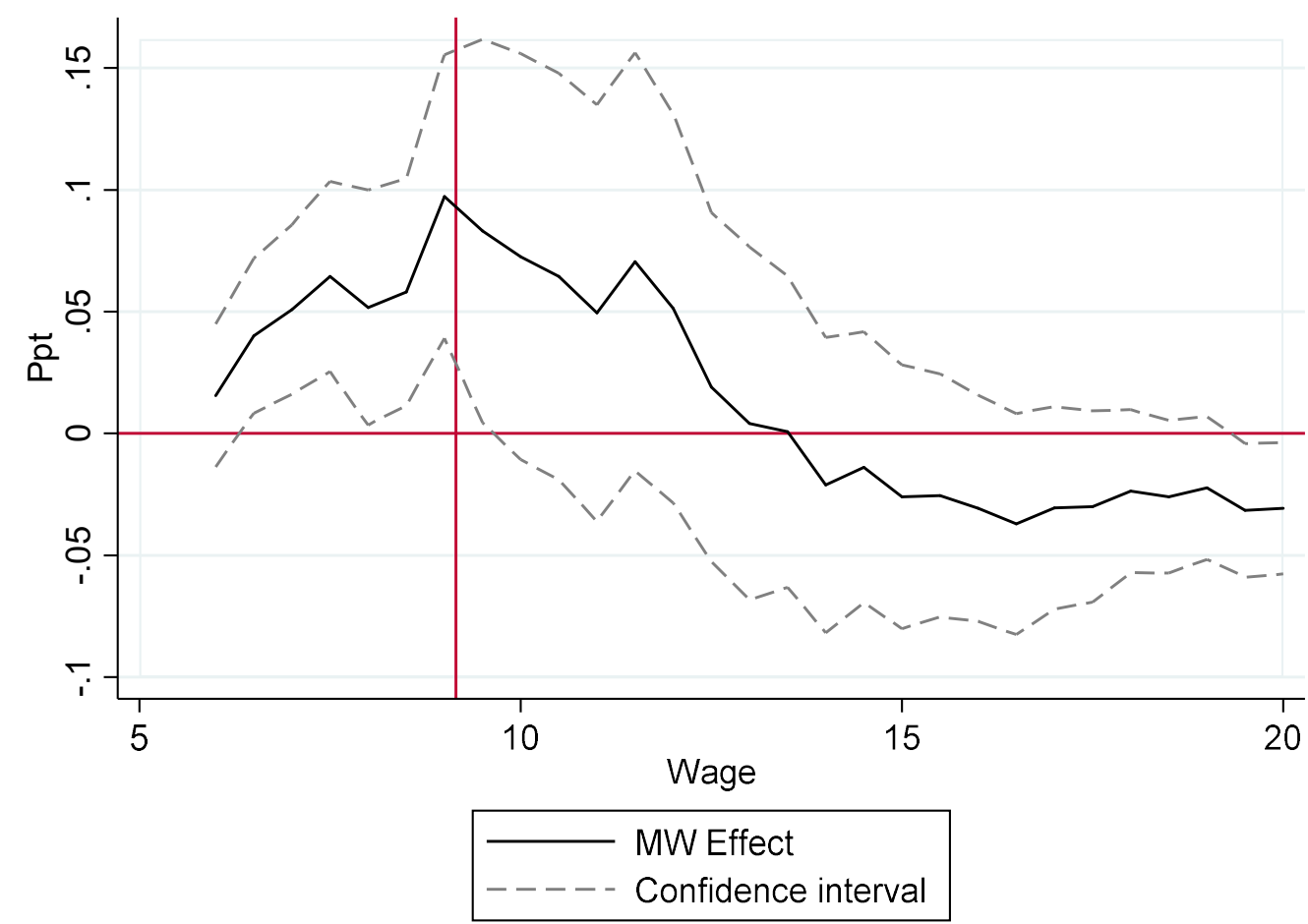

Note: $\quad$ The vertical red line indicates the 2016 minimum wage (€9.15). The dashed grey lines indicate the region in the distribution where the minimum wage effect is statistically significant $(€ 6.50-€ 9.50)$. Ppt = percentage points. 


\begin{tabular}{|l|c|c|}
\hline Young workers (25 years of age or less) & $\mathbf{2 0 1 6}$ & Counterfactual \\
\hline P90/P10 & 1.87 & 2.46 \\
\hline P75/P25 & 1.37 & 1.43 \\
\hline Average wage in range $€ 6.50-€ 9.50$ & 8.90 & 8.59 \\
\hline Observations & 787 & 787 \\
\hline
\end{tabular}

Source: SILC (2010-2016).

\subsection{THE EFFECT OF THE MINIMUM WAGE CHANGE ON HOUSEHOLD INCOME}

Figure 3.7 indicates that the $\mathbf{2 0 1 6}$ minimum wage increase had little effect on the gross household income distribution, using either measure of income. The minimum wage effect oscillates around zero and is not statistically significant at any point of the annual equivalised gross income distribution. The effect is also close to zero for most of the equivalised monthly gross employment income distribution (ranging from $€ 0$ to $€ 5,000$ per month) although a small, positive and marginally statistically significant effect is observed at one point ( $€ 800$ per month). ${ }^{20}$ Therefore, there is no strong evidence to indicate that the increase in the minimum wage impacted household income. While we observe strong effects when looking at the hourly wage distribution of individual employees, the fact that minimum wage workers are located along the entire household income distribution, and are typically not primary earners within households, means that these effects do not translate into household income. This is in line with some of the recent literature on the relationship between the level of the minimum wage and income inequality (Logue and Callan, 2016; MaCurdy, 2015; Caliendo et al., 2017).

\footnotetext{
${ }^{20}$ This effect at this point is not statistically significant at the $5 \%$ level, but is significant at the $10 \%$ level.
} 


\section{FIGURE 3.7 EFFECT OF MINIMUM WAGE INCREASE ON HOUSEHOLD INCOMES}
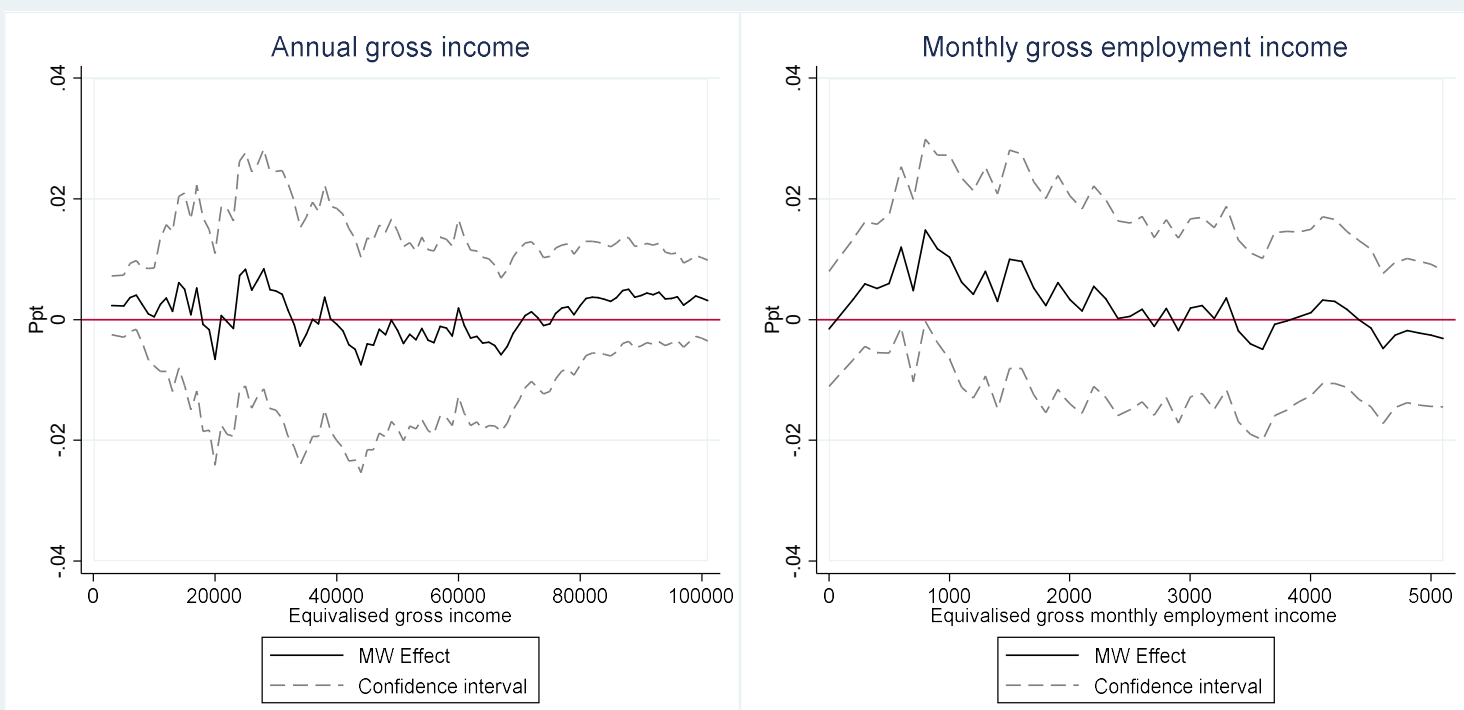


\section{CHAPTER 4}

\section{Conclusion}

Minimum wage policies help to ensure fair pay for low-paid workers with low bargaining power. While the international evidence tends to show that minimum wages can reduce inequality, the extent of their effectiveness has been questioned. Some studies conclude that minimum wage policies are inefficient at tackling inequality and poverty, and the Low Pay Commission has acknowledged that the minimum wage may be a blunt tool in this regard.

In this report we investigate the effect of the 2016 increase in the Irish national minimum wage on the hourly wage and gross household income distributions. Our evidence indicates that the minimum wage was effective in increasing the wages of low-paid workers and in reducing hourly wage inequality. Our results show that, in the absence of a minimum wage change, approximately $10 \%$ of workers in 2016 would have earned $€ 9.15$ per hour (the $2016 \mathrm{NMW}$ ) or below. However, following the minimum wage change, approximately $6 \%$ of workers had an hourly wage in this range. Therefore, the minimum wage change is associated with a 4 percentage point reduction in the number of employees earning below €9.15 per hour. The effect for young workers was more pronounced, at 10 percentage points. With regard to hourly wage inequality, the 2016 increase was associated with a reduction of approximately $8 \%$ in the P90/P10 ratio and approximately $4 \%$ in the P75/P25 ratio.

We detect results consistent with positive wage spillover effects to workers earning in excess of the new 2016 minimum wage. There are statistically significant wage effects as far up the wage distribution as $€ 11.50$ per hour. While measurement error may, to some degree, influence these results, the strength of the findings is suggestive of genuine spillover effects. We find no effect of the 2016 minimum wage increase on the gross household income distribution.

From the perspective of policy, the research indicates that while the impact of the minimum wage is most heavily concentrated in the immediate area of the rate change, there may also be spillover effects resulting in wage increases in the lowest $25 \%$ of the wage distribution. The presence of such spillovers would amplify the effect of minimum wage changes on hourly wage inequality by boosting the wages of a wider range of low-paid workers. However, the presence of spillover effects also suggests that the impact of minimum wage changes on aggregates such as employment, hours worked and labour costs requires careful and ongoing monitoring. The significant spike observed in the distribution of earnings is suggestive of a high level of compliance with the 2016 minimum wage ruling and 
22 | National Minimum Wage and Distribution of Hourly Wages and Household Income

this, in turn, is likely to have heightened the estimated impact of the policy on reduced earnings inequality. 


\section{APPENDIX}

\section{Formal explanation of the distributional regression approach}

Distributional regression (DR) is theoretically equivalent to the more commonly used quantile regression (QR) technique (Koenker et al., 2013). However, unlike $Q R$, inference using $D R$ is not affected by the bunching of data around the minimum wage. Additionally, empirical evidence suggests that DR generally provides a better fit to wage distributions than quantile regression (Rothe and Wied, 2013; Van Kerm et al., 2016).

More formally, we are interested in the change in the distribution of wages observed before and after the increase in the MW, given explanatory variables such as age and education, holding the marginal distribution of these covariates constant. Marginal wage distributions are directly derived by integration of the conditional distributions over human capital characteristics:

$$
F_{t}^{t}(w)=\int_{\Omega_{x}} F^{t}(w \mid x) h_{t}(x) d x
$$

where $F^{t}(. \mid x)$ is the conditional wage distribution function given human capital and job characteristics $x$ at period $t$, and $h_{t}$ is the density distribution of human capital and job characteristics in period $t$. So, $F_{t}^{t}(w)$ can either be an observed or a counterfactual marginal wage distribution where the superscript refers to the conditional wage distribution and the subscript refers to the covariate distribution. The conditional wage distribution can relate to before $(t-1)$ or after $(t)$ the increase in the $\mathrm{MW}$, and the covariate distribution can also relate to before $(t-1)$ or after $(t)$ the increase in the MW.

Taking the example of $F_{t}^{t}(w)$, which is the marginal wage distribution of before workers, with before characteristics, sample estimates are obtained by replacing $F^{t}(. \mid x)$ by estimates $\hat{F}^{t}(. \mid x)$ derived from the predictions of a probit model (at $w$ ) estimated on the before sample and by averaging the predictions over our sample of $N$ before workers before the increase in the MW:

$$
F_{b}^{b}(w)=\frac{1}{N_{b}} \sum_{i=1}^{N_{b}} \hat{F}^{b}\left(w \mid x_{i}\right)
$$


The separation of conditional wage distributions and the distribution of characteristics offers a straightforward way to create counterfactual marginal wage distributions. For example,

$$
F_{a}^{b}(w)=\frac{1}{N_{a}} \sum_{i=1}^{N_{a}} \hat{F}^{b}\left(w \mid x_{i}\right)
$$

is a counterfactual distribution that represents the distribution that would be observed among workers after the increase in the MW if they were paid according to the conditional wage distributions from before the increase. Predictions are based on a probit model estimated over the before sample but averaged over the after sample.

The difference in wage distributions between the before and after periods is:

$$
\widehat{D D}(w)=F_{a}^{a}(w)-F_{b}^{b}(w)
$$

Using the counterfactual marginal wage distribution defined in Equation (3), this can be decomposed into a price and a composition effect. The price effect identifies the effect of the increase to the minimum wage on the wage distribution while the composition effect reflects changes in the demographic structure of the population, including any changes to the structure of labour supply due to the increase in the minimum wage.

$$
\widehat{D D}(w)=\underbrace{\left[F_{a}^{a}(w)-F_{a}^{b}(w)\right]}_{\text {price }}+\underbrace{\left[\left(F_{a}^{b}(w)-F_{b}^{b}(w)\right]\right.}_{\text {composition }}
$$




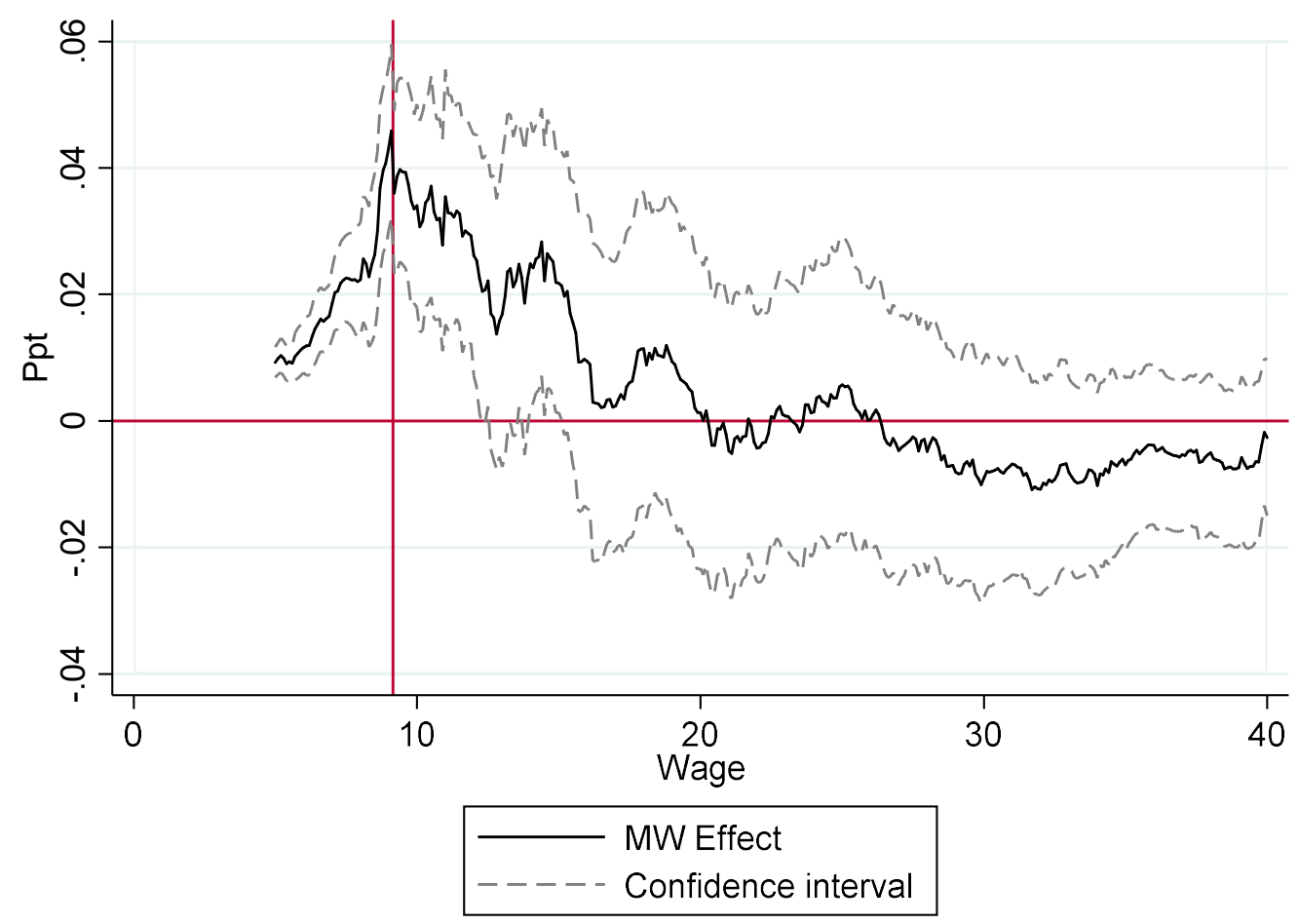

Note: $\quad P p t=$ percentage points.

FIGURE A.2 PLACEBO ANALYSIS (2013-2014 AND 2014-2015)
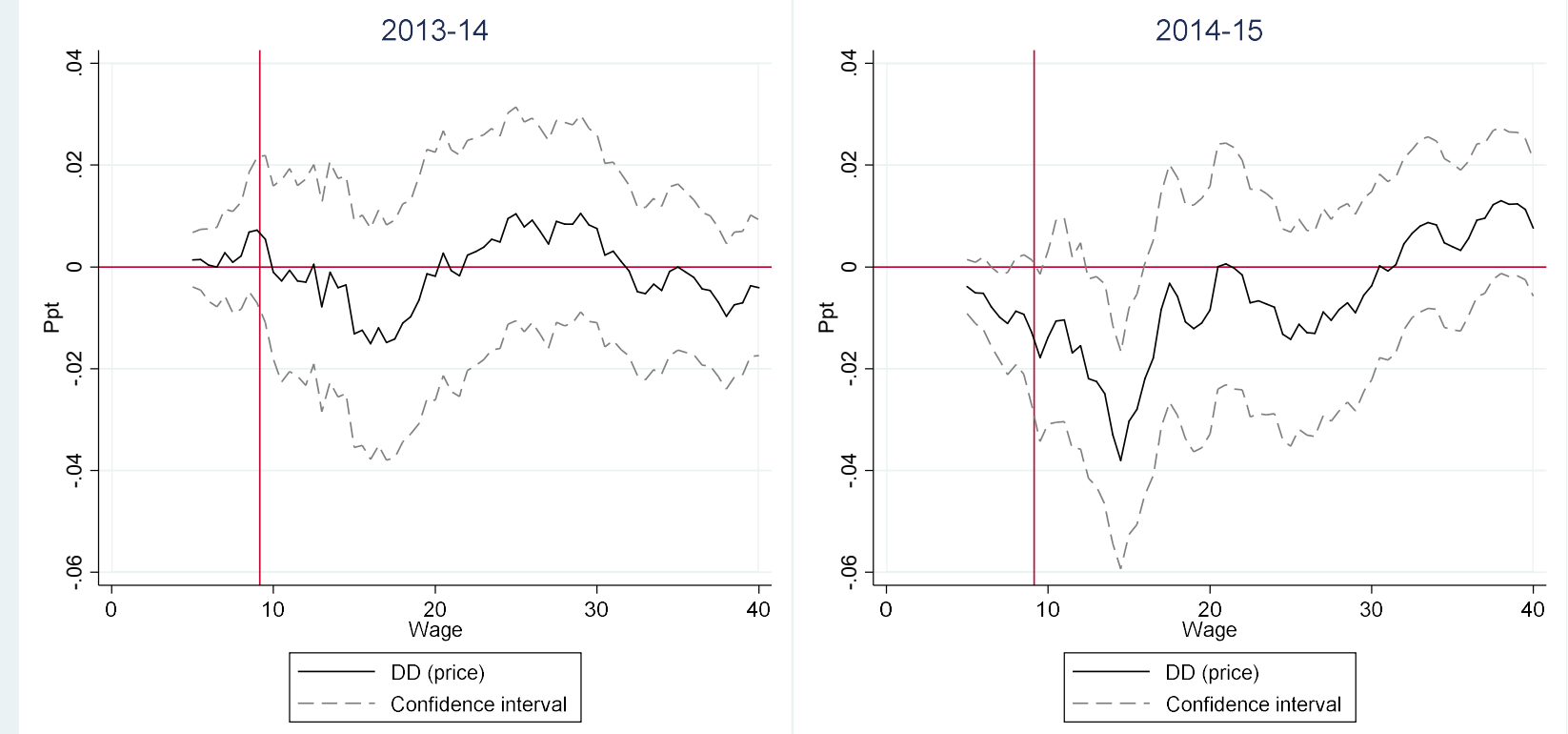



\section{REFERENCES}

Autor, D.H., A. Manning, and C.L. Smith (2016). 'The contribution of the minimum wage to US wage inequality over three decades: a reassessment', American Economic Journal: Applied Economics, Vol. 8, No. 1, pp. 58-99.

Bargain, O., K. Doorley, and P. van Kerm (2018). 'Minimum wages and the gender pay gap: evidence from the UK and Ireland', Review of Income and Wealth, forthcoming.

Belman, D., P. Wolfson, and K. Nawakitphaitoon (2015). 'Who is affected by the minimum wage?', Industrial Relations: A Journal of Economy and Society, Vol. 54, No. 4, pp. 582-621.

Caliendo, M., A. Fedorets, M. Preuss, C. Schröder, and L. Wittbrodt (2017). The short-term distributional effects of the German minimum wage reform, IZA Discussion Paper 11246, Bonn: Institute for the Study of Labor (IZA).

Dickens, R. and A. Manning (2004a). 'Has the national minimum wage reduced UK wage inequality?', Journal of the Royal Statistical Society: Series A, Vol. 167, No. 4, pp. 613-626.

Dickens, R. and A. Manning (2004b). 'Spikes and spill-overs: the impact of the national minimum wage on the wage distribution in a low-wage sector', Economic Journal, Vol. 114, No. 494, pp. C95-C101.

Garnero, A., S. Kampelmann, and F. Rycx (2015). 'Minimum wage systems and earnings inequalities: does institutional diversity matter?', European Journal of Industrial Relations, Vol. 21, No. 2, pp. 115-130.

Holton, N. and D. O'Neill (2017). 'The changing nature of Irish wage inequality from boom to bust', Economic and Social Review, Vol. 48, No. 1, pp. 1-26.

Koenker, R., S. Leorato, and F. Peracchi (2013). Distributional vs. quantile regression, Research Paper 11-15-300, Rome: Centre for Economic and International Studies.

Logue, C. and T. Callan (2016). Low pay, minimum wages and household incomes: evidence for Ireland, Dublin: The Economic and Social Research Institute.

Low Pay Commission (2016). Recommendations for the national minimum wage, Dublin: Low Pay Commission.

MaCurdy, T. (2015). 'How effective is the minimum wage at supporting the poor?', Journal of Political Economy, Vol. 123, No. 2, pp. 497-545.

Maurizio, R. and G. Vazquez (2016). 'Distribution effects of the minimum wage in four Latin American Countries: Argentina, Brazil, Chile and Uruguay', International Labour Review, Vol. 155, No. 1, pp. 97-131.

McGuinness, S. and P. Redmond (2018). Estimating the effect of an increase in the minimum wage on hours worked and employment in Ireland, Dublin: The Economic and Social Research Institute. 
Neumark, D., M. Schweitzer, and W. Wascher (2004). 'Minimum wage effects throughout the wage distribution', Journal of Human Resources, Vol. 39, No. 2, pp. 425-450.

Rothe, C. and D. Wied (2013). 'Misspecification testing in a class of conditional distributional models', Journal of the American Statistical Association, Vol. 108, No. 501, pp. 314-324.

Van Kerm, P., S. Yu, and C. Choe (2016). 'Decomposing quantile wage gaps: a conditional likelihood approach', Journal of the Royal Statistical Society: Series C (Applied Statistics), Vol. 65, No. 4, pp. 507-527. 
Whitaker Square,

Sir John Rogerson's Quay, Dublin 2

Telephone +35318632000

Email admin@esri.ie

Web www.esri.ie

Twitter @ESRIDublin

ISBN 978-0-7070-482-2 